\title{
The role of the sialic acid in monitoring the evolution of malignant melanoma. From murine models to human research
}

\author{
Rolul acidului sialic în monitorizarea evoluției melanomului malign. \\ De la modele murine la cercetarea umană
}

\author{
Andreea Veronica D. Lazescu ${ }^{1 *}$, Maria Iuliana I. Gruia ${ }^{2}$, Rodica M. Anghel ${ }^{1}$, \\ Daniela A. Glavan ${ }^{2}$ \\ 1. University of Medicine and Pharmacy "Carol Davila" Bucharest, Oncology Department \\ 2. Institute of Oncology "Prof. Dr. Alexandru Trestioreanu" Bucharest
}

\begin{abstract}
Purpose: To identify sialic acid as a tumor marker to be used in experimental models. Obtained data will be extrapolated to humans, so that this marker can be used in clinical practice. Materials and methods: We used B16 melanoma cells. The lot was composed of 30 male C57Bl6 mice, which received subcutaneous injections of $5 \times 105$ B16 melanoma cells into the right flank. Tumor volume was measured with a vernier caliper. Sialic acid was determined from the serum obtained by cardiac puncture. The second step of our research was performed on a number of 25 patients with cutaneous melanoma. Determination of sialic acid was performed using the Kattermann colorimetric method. The correlation between sialic acid and disease progression was exemplified in two clinical cases. Sialic acid determination was performed dynamically from diagnosis, following disease progression. Results: In murine models tumors increased after a lag period of up to 10 days. Tumor growth was recorded by measuring the tumor's diameters and calculating its volume. We observed a progressive increase of sialic acid in parallel with tumor volume. In human subjects, sialic acid levels increase in metastatic disease and are common in localized disease. In the two clinical cases there was a very strong correlation between sialic acid and disease progression. Conclusions: B16 melanoma cells are highly metastatic. Sialic acid level was increased in metastatic tumor animals compared to normal animals. Higher levels of sialic acid have been shown to correlate with the metastatic potential of tumor cells. For humans, determination of total serum sialic acid would be more useful for diagnosis of advanced melanoma stage rather than for early detection and screening.
\end{abstract}

Keywords: melanoma, sialic acid, marker, murine models, metastatic

\section{Rezumat}

Scopul lucrarii: De a demonstra ca acidul sialic poate fi utilizat ca marker tumoral in monitorizarea evolutiei melanomului la modelele experimentale. Datele obtinute s-au extrapolat la om, astfel incat acest mar-

"Corresponding author: Andreea Veronica D. Lazescu - University of Medicine and Pharmacy "Carol Davila" Bucharest, Oncology Department, Institute of Oncology “Prof. Dr. Alexandru Trestioreanu”, Fundeni Road no.252, district 2, Bucharest.

Fax: (+40) 021/2271242, E-Mail: andreea.lazescu@gmail.com, Mobile phone: +40721336483 
ker sa poata fi folosit in practica medicala. Material si metode: S-au utilizat linii celulare experimentale tip B16 de melanom. Lotul a fost alcatuit din 30 de soareci masculi de tip C57Bl6 care au primit un numar de 5x105 celule tumorale prin injectare in flancul drept. Volumul tumoral a fost masurat cu un caliper vernier. Acidul sialic $s$-a determinat din ser obtinut prin punctie cardiaca. A doua parte a studiului s-a desfasurat pe un numar de 25 de pacienti cu melanom. Acidul sialic s-a determinat prin metoda colorimetrica Katterman. Corelatia dintre progresia bolii si acidul sialic a fost ulterior exemplificata prin doua cazuri clinice. Determinarea acidului sialic s-a efectuat in dinamica progresiei bolii. Rezultate: La modelele murine cresterea tumorala s-a inregistrat dupa o perioada de lag de 10 zile si s-a evidentiat prin masurarea diametrelor si volumelor tumorale. Am observat o crestere direct proportionala a acidului sialic. La subiectii umani nivelele serice au crescut in boala metastatica si au ramas normale in boala localizata. In cele doua cazuri clinice s-a observat o corelatie stransa intre progresia bolii si acidul sialic. Concluzii: celulele B16 de melanoma au potential inalt de metastazare. Nivelele de acid sialic sunt crescute la soarecii cu metastaze. Nivelele crescute de acid sialic se coreleaza cu potentialul metastatic al tumorii. La oameni, acidul sialic creste in fazele avansate ale bolii si nu are utilitate in depistare sau screening.

Cuvinte cheie: melanom, acid sialic, marker, modele murine, metastaze.

Received: $7^{\text {th }}$ August 2012; Accepted: 15 $5^{\text {th }}$ April 2013; Published: $15^{\text {th }}$ June 2013.

\section{Introduction}

Malignant melanoma is one of the most aggressive forms of skin cancer, characterized by malignant proliferation of melanocytes (1). The vast majority of melanomas are from the skin but malignant melanomas have been described in nearly every organ of the body: choroidal melanoma, melanoma of the central nervous system (2), mucosal melanoma, head and neck melanoma, gastrointestinal melanoma, genitourinary melanoma (3), melanoma of unknown primary site (4). Early diagnosis and surgical excision can prevent melanoma evolution (5).

Some substances associated with malignant tumors can be identified in blood, function- ing as markers of tumor cell activity(6), with a real clinical significance, being useful in diagnosis and monitoring the evolution of disease, but also in monitoring response to treatment (7). They are also useful in periodic reassessment of post-therapy patients. Elevated blood levels can suggest a possible local recurrence or distant metastasis (8). Over time, several markers were identified: tumor-associated antigens, hormones, enzymes or immunoglobulins (9).

- Tumor-associated antigen: CA125 (ovarian cancer), CA 15-3 (breast cancer), PSA (prostate cancer) (10);

- Hormones: HCG (human chorionic gonadotropin) (11), ACTH (adrenocorticotropic hormone), LPH (lipotropic hormone), $\mathrm{MSH}$

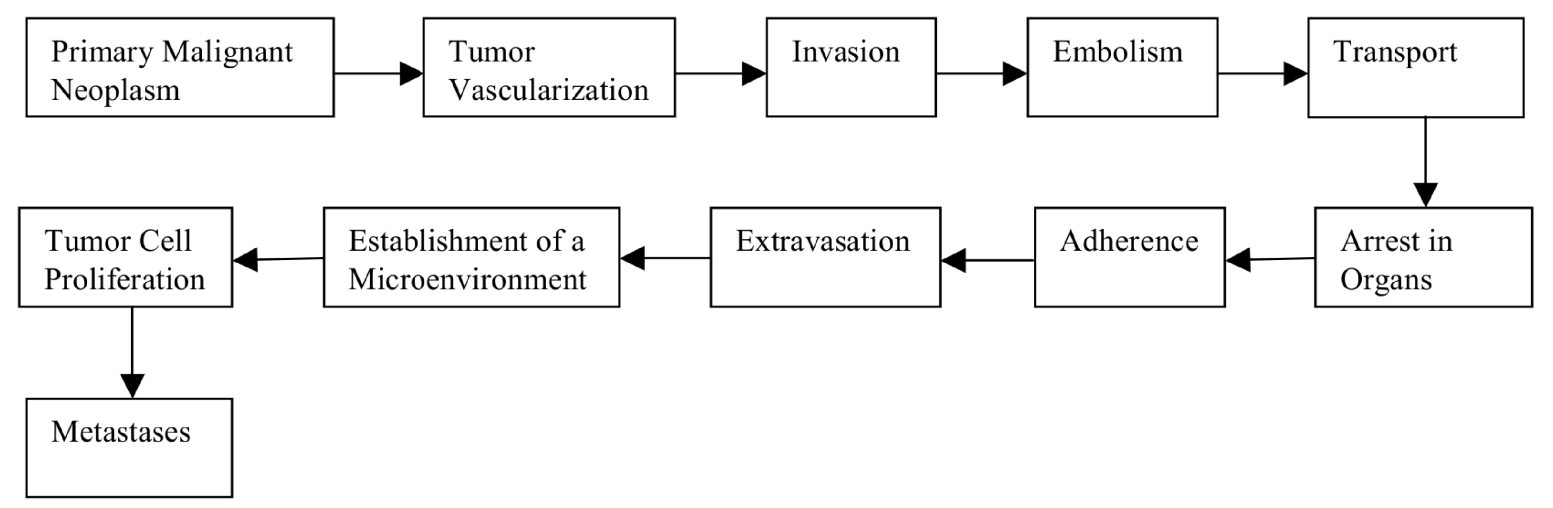

Figure 1. Natural evolution of malignant melanoma (1) 
(melanocyte-stimulating hormone), ADH (antidiuretic hormone), TSH (thyroid-stimulating hormone), VIP (vasoactive intestinal peptide), glucagon, calcitonin (12);

- Enzymes: ALP (alkaline phosphatase), LDH (lactic dehydrogenase), GGT (gamma-glutamyl transpeptidase) (13).

Tumor markers have a diagnostic role in early detection (screening), disease staging, prognostic, monitoring response to treatment and disease relapse (14). Not all malignancies are accompanied by specific markers (lung cancers) (15), but there are malignancies characterized by the presence of markers with high specificity and sensitivity like AFP (alpha fetoprotein) in testicular carcinoma(11).

Lately research efforts in malignant diseases have focused more on the discovery of new molecular targeted therapies (16). However, we should not forget the usefulness of identifying other tumor markers with high specificity and sensitivity in detection, diagnosis, treatment and monitoring of malignant tumors.

Many studies tried to establish a correlation between elevated levels of sialic acid ( $\mathrm{N}$ acetylneuraminic acid) and the presence of malignant cells (17). Sialic acid is a nonspecific tumor marker (18). Increased membrane density of sialic acid and associating increased activity of sialyltransferases were observed in several types of malignant cells (19). There appears to be an association between high levels of sialic acid and tumor growth in malignant melanoma (20). High density of sialic acid on the surface of transformed tumor cells was identified in animal models but also in humans (21). The idea that serum sialic acid levels may be a sign of melanoma tumor growth represents a matter of clinical interest (22).

Sialic acid is a generic term of $\mathrm{N}$ - or Osubstituted derivatives of neuraminic acid, a monosaccharide with a nine-carbon backbone (23). It is also the name for the most common member of this group, $\mathrm{N}$-acetylneuraminic acid (Neu5Ac or NANA)(24).

It is already known that metastatic can- cer cells often express a high density of sialic acid-rich glycoproteins (25). This helps these late-stage cancer cells enter the blood stream (26, 27). Sialic acid also plays an important role in human influenza infection (28), and can "hide" mannose antigens on the surface of host cells bacteria from mannose-binding lectin. This aspect prevents the activation of complement (29).

\section{Materials and methods}

The purpose of this paper is to identify sialic acid as tumor marker to be used in experimental models. These data will be extrapolated to humans, so that this marker can be used in clinical practice. Elevated serum sialic acid levels may indicate disease progression, namely the appearance of metastasis.

We used B16 melanoma cells. The transplantable B16- melanoma cells were obtained from the Institute of Biochemistry from Bucharest and adapted to grow in culture. Melanocytes were grown in a humidified atmosphere at $37^{\circ} \mathrm{C}$ under $5 \% \mathrm{CO}_{2}$. The cell suspension was centrifuged at $1000 \mathrm{rpm}$ (rotations per minute) and the supernatant and the rest of destroyed cells were removed. The cell sediment was suspended in a sterile isotonic solution and the suspension was adjusted to a concentration of $5 \times 10^{6}$ viable cells. The lot was composed of 30 male C57B16 6-8 weeks old mice, weighing 16-20 g. Transplanted mice were slightly anesthetized with chloroform. Mice were shaved before receiving a subcutaneous injection into the right flank. This area was sterilized and a small skin incision was performed. Mice received a subcutaneous injection of $5 \times 10^{5}$ B 16 melanoma cells. After 14 days from cell transplantation the tumor was palpable in the right flank. Mice were sacrificed for measurement and sialic acid determination after 3, 4, 5, 6, 7 weeks. Tumor volume V was measured with a vernier caliper.

Statistical analysis

For the statistical analysis we use ANOVA test. Sample sizes between groups do not 
have to be equal, but large differences in sample sizes by group may affect the outcome of the multiple comparisons tests. We determine specific difference performing paired analyses of the group, two at a time using also Bonferonni adjustment. In this output, the test statistic, F, is reported in the analysis of variance table. The $\mathrm{p}$ value for this statistics is $p<0.001$, This means that there is evidence that there are differences in the means across groups.

The study respected the Animals and Treatment Protocols. In concordance with the theme of "Ethics in Scientific Research" Conference held in Bratislava in 2002 and the Royal Society for the Prevention of Violence against Animals from United Kingdom, we sustain that the pain induced to experimental animals during theresearche could influence correct data through stress reaction modifications. As such, we attempted to reduce the level of pain inflicted to animals during the experiments (the limited pain principle); we also reduced the number of animals investigated, using the lowes number possible (the reducing principle). In the case of experimental data on small rodents, the concept of the experiment and the control methods must be in concordance with the importance of the investigated issue and must allow the determination of security limits. The evaluation of toxic effects is based on behavioral observations, growth, hematological and biochemical assays, and also on autopsy reports analysis and histological data. The experimental in vivo models were elaborated with legal aid based on Decision No.63/2002 on the principles of good laboratory practice, and on inspections and verifications of the enforcement of this decision order during chemical substances use and tests. Other orders used were the 263/2003, the Committee Directive no. 86/609/CEE onthe protection of laboratory animals used in experimental purposes or in other scientific purposes, the $471 / 2002$ law on the use of the 37/2002 order for protection of experimental animals and the $143 / 2002$ order on instructions regarding the shelter and the care of scientifically used animals. According to the Founding Act of the Institute of Oncology Bucharest (1949) there is a single protocol for the use of laboratory animals, involving the Committee of Ethics and Methodologies for working with animals.

The second step of our research was performed between May 2011 and June 2012 on a number of 25 patients with cutaneous melanoma (14 male and 11 female) in the age group between 18 and 55 years. The study was approved by the Ethics Committee of the Institute of Oncology from Bucharest. All patients included in the study are in the evidence of the Institute of Oncology from Bucharest and signed informed consents to participate in this study.

Inclusion criteria: age over 18 years, good performance status, ECOG=0-2, good renal, cardiac and hepatic function; good hematological and biochemical balance; histologically confirmed diagnosis of malignant melanoma; localized or metastatic disease without brain metastases; no history of cancer. Patients were divided into two groups, the first group containing patients with localized disease (10 patients) and the second group patients with metastatic disease (15 patients).

Determination of sialic acid for the two groups was made using the colorimetric method described by Kattermann (30). Sialic acid is first subjected to periodic oxidation, resulting in formation of $\beta$-formylpyruvic acid; this acid reacts with 2 molecules of thiobarbituric acid to form a pink cromophore with maximum absorbance at $549 \mathrm{~nm}$. The normal values of serum sialic acid: $1.41-2.15 \mathrm{mmol} / \mathrm{l}$.

Age and sex have no influence on serum sialic acid levels.

\section{Results}

The morphofunctional characteristics of the experimental tumors obtained show a discolored liver, friable, enlarged spleen, obvious splenic follicles, discolored brittle kidneys, lungs with congestive-hemorrhagic areas, en- 


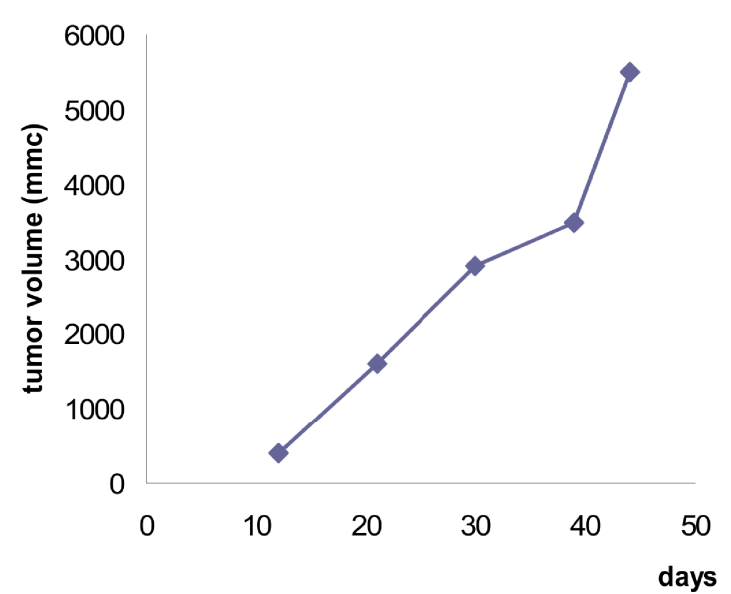

Figure 2. Dynamic evolution of the tumor volume (mouse with B16 melanoma)

larged tracheobronchial lymph nodes and macroscopic lung metastases.

Tumors increased after a lag period up to 10 days. Tumor growth was recorded by measuring the tumor's diameters and calculating its volume. The values obtained are presented in Figure 2.

Values are represented as an average of 5 determinations + /-SD. $\mathrm{P}$ was determined by ANOVA test ( $p<0.001$ was considered significant).

Determination of sialic acid in experimental tumor growth dynamics

In the dynamic evolution of the tumor volume experimental animals were sacrificed. Sialic acid was determined with the method presented, from serum obtained by cardiac puncture. The data obtained are shown in Figure 3.

The values are represented as an average of 5 determinations + /-SD. P was determined by ANOVA test ( $p<0.001$ was considered significant).

Measurements performed dynamically correlated with increased levels of sialic acid. Therefore, there is consistency between tumor volume and production of glycoproteins and sialic acid by tumor cells, Pearson $r$ factor is 0.96 . About 10 days after tumor cell injection in the right flank we could observe a progressive increase of sialic acid in parallel with tumor volume. Values were very high at 42 days, which coincided with metastatic disease.

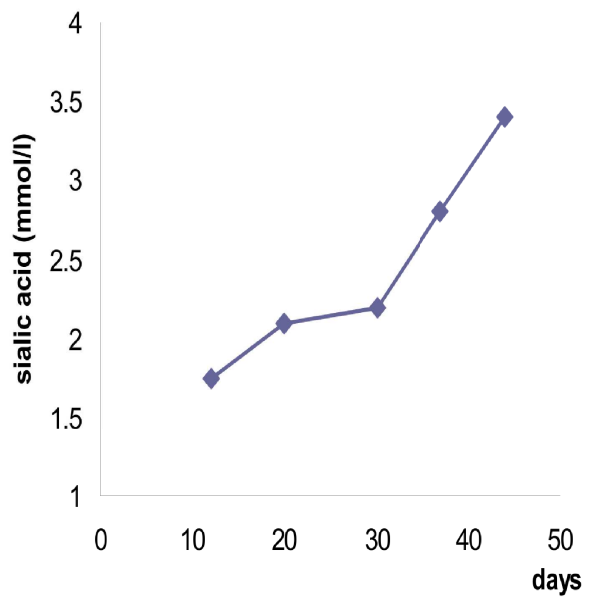

Figure 3. Dynamic determination of sialic acid (mouse with B16 melanoma)

In murine melanoma, sialic acid appears to be a useful marker in monitoring tumor growth and development.

\section{Determination of sialic acid in pa- tients with malignant melanoma}

The next step of the study was to measure levels of sialic acid in 25 patients (11 women and 14 men), mean age 46.7 years, divided into two groups: 15 patients with metastatic disease and 10 patients with localized disease. The 15 patients with extensive disease had metastasis at various levels: lung, liver, lymph, skin.

We observed that in patients with localized disease serum sialic acid levels were within normal limits (with a mean value of $2.16+/-0.1$ $\mathrm{mmol} / \mathrm{l}$ ), unlike the metastatic group that had elevated serum levels (with an mean value of 3.50 $+/-1.2 \mathrm{mmol} / \mathrm{l})$. This observation suggests that sialic acid levels increase in metastatic disease and are common in localized disease. Therefore, sialic acid may be an indicator of metastatic disease but cannot be used as a marker for early detection.

To support this idea, we exemplified in two clinical cases. The sialic acid determination was performed dynamically from diagnosis, followingthe progression of the disease.

The first case wass that of patient ZA, 18 years, male, no other secondary diseases, 


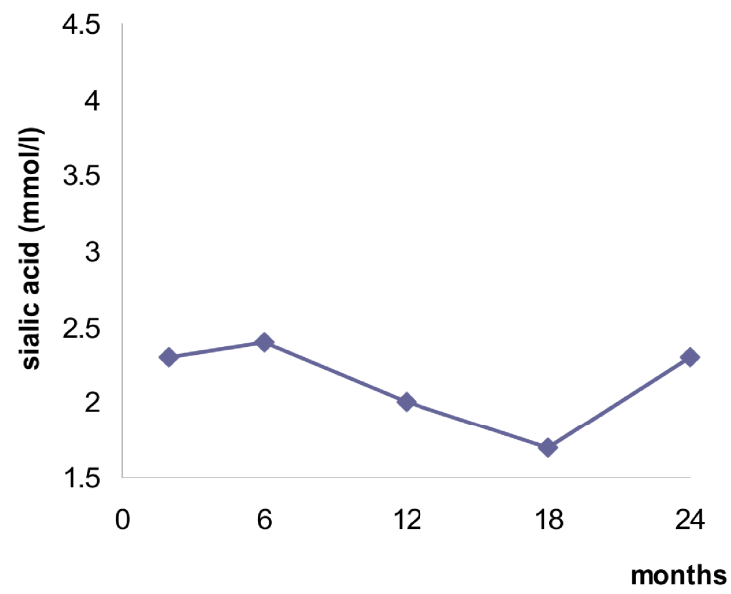

Figure 4. Dynamic determination of sialic acid (First case - Z.A., 18 years, male)

good performance status ECOG=0, good renal, cardiac and hepatic function, good hematological and biochemical balance, diagnosed in March 2009 with malignant melanoma (histologically confirmed) of the torso and lymphatic metastases. Sialic acid value at diagnosis was $2.4 \mathrm{mmol} / \mathrm{l}$. The patient received extensive surgery with lymph node dissection and chemotherapy with dacarbazine and cisplatin for 6 months. Evolution was favorable for 12 months, without signs of disease progression. During this period we have observed a decrease in the serum levels of sialic acid to a value of $1.8 \mathrm{mmol} / \mathrm{l}$. At 18 months after diagnosis there was a progressive increase of sialic acid levels. After another 4 months the patient was diagnosed with lung metastases by CT scan. At 24 months after diagnosis two liver metastases were found. At this time the value of sialic acid was $2.2 \mathrm{mmol} / \mathrm{l}$. These dynamic values are represented in Figure 4.

The second case is that of patient VG, 53 years, male, no other secondary diseases, good performance status, ECOG=0, good renal, cardiac and hepatic function, good hematological and biochemical balance, diagnosed in December 2009 with malignant melanoma (histologically confirmed) of the right arm and neg-

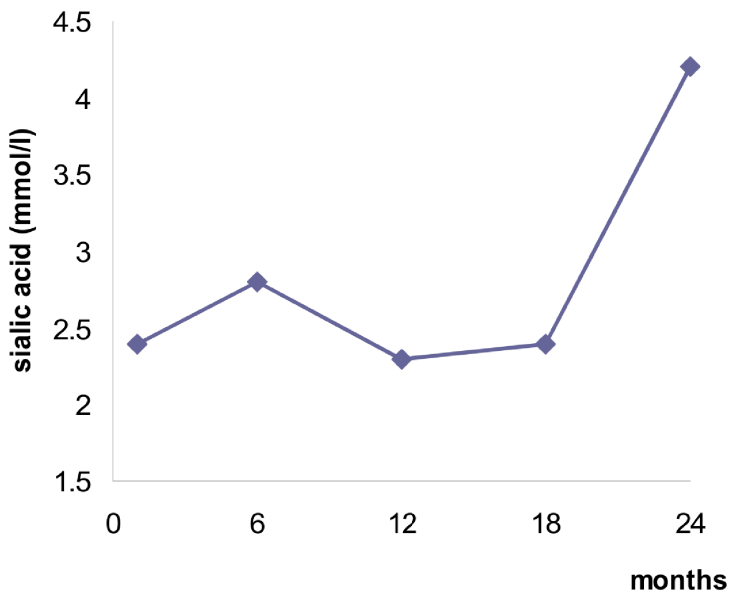

Figure 5. Dynamic determination of sialic acid (Second case - V.G., 53 years, male)

ative sentinel node. He underwent wide surgical excision. Sialic acid value at diagnosis was 2.3 $\mathrm{mmol} / \mathrm{l}$; the value continued to grow, so that at 6 months after surgical excision sialic acid value was $2.8 \mathrm{mmol} / \mathrm{l}$. The patient was diagnosed with enlarged right axillary lymph nodes. Axillary lymph nodes dissection was performed. The patient followed six series of PCT with dacarbazine and cisplatin with favorable evolution. The sialic acid remained constantly elevated for 18 months, from diagnosis until it began to grow again. After 24 months the patient was already diagnosed with multiple metastases of liver, lung, skin and lymph nodes. At that moment the value of sialic acid was $4.2 \mathrm{mmol} / \mathrm{l}$. These dynamic values are represented in Figure 5.

In both cases we can see a very strong correlation between sialic acid and disease progression, particularly the appearance of distant metastases. This observation reinforces the idea that sialic acid could be a marker of disease progression, marking the the appearance of metastatic disease.

\section{Discussions}

Sialic acid has been shown to play important roles in a variety of biological processes including cell adhesion, cellular recognition and 
regulation of glycoconjugates functions (3336). In melanoma cells, the involvement of sialic acid residues in determining metastatic potential has been well documented (31).

The levels of sialic acid, an acetylated derivative of the neuraminic acid which is often found increased in neoplasm and are shed or secreted by tumor cells and thus are increased in blood (32).

Neuraminic sialic acids are 9-carbon sugars typically found in the glycocalyx that take part in the modulation of malignant cell behavior (37, 38). They are usually found as a terminal component of different membrane glycoconjugates, such as glycoproteins or glycolipids. Major examples are mucins and gangliosides, both implicated in the modulation of cell behavior $(39,40)$. The most common sialic acids in mammals are $\mathrm{N}$-acetylneuraminic (NeuAc) and N-glycolylneuraminic (NeuGc) acids. The only structural difference between them is a single oxygen atom at the C-5 position of NeuGc catalyzed by the cytidine monophospho-N-acetylneuraminic acid hydroxylase (CMAH) (41). While NeuGc is expressed in most somatic mouse cells, there is nearly no information regarding its expression in mouse cancer tissues (42). Few reports suggest a null presence of this sugar in murine malignant cells (43).

Considering that most normal mouse somatic cells are positive for the expression of this gene, it is an interesting fact that malignant cells lack such expression. Sialic acids are overexpressed as part of gangliosides in several malignancies and their involvement in the malignant cell behavior has been previously reported $(44,45)$. The lack of expression of NeuGc in mouse tumor cells suggests that the silencing of the CMAH gene is an important step in the cell transformation process in this species (42).

The results obtained in animal models correlate quite well with those obtained in human subjects. About 10 days after tumor cell injection in the right flank, sialic acid values began to increase in proportion to tumor volume. Values were very high after 42 days. These data correlated well with the presence of numerous lung, liver, lymph, kid- ney and spleen metastases. In human subjects we can observe the same trend of increase in serum sialic acid when disease progression and distant metastasis occurred. This correlation between growth in tumor volume, the appearance of metastases and increased sialic acid values seems quite fair. Unfortunately, the group of patients was relatively small, because the goal of our study was to obtain a more homogeneous lot. Selected patients have the same features of the disease, without major variations to interfere and influence the results. Therefore, for more reliable results we need more studies on larger groups of patients. Tumors transplanted in mice do not have the same characteristics as human tumors, but the goal of translational research is to extrapolate these data to human research and translate laboratory results into clinical practice. Therefore, in this study we used genetically pure lines of mice, specially designed in the laboratory. The malignant tumors biology in experimental animals is not identical to human cancer biology. The malignant tumors of experimental animals show a reduced capacity of spontaneous metastasis compared to human ones. The growth rate of cancers in animals is faster (adapted to the life expectancy of the species). For this reason, extrapolation of results to humans is not always possible. However, experimental animals research is the only valid way of decoding the many processes involved in the development and evolution of malignant tumors.

Determination of sialic acid is an older method, but manageable for both doctor and patient. It is also inexpensive. Therefore, it could be introduced into clinical practice.

Unlike genomic techniques that can be performed only once at the time of tissue sampling, sialic acid can be determined dynamically. Being inexpensive and easily approachable, this technique could be used in monitoring the evolution of malignant melanoma. Increasing sialic acid levels may indicate disease progression and the presence of systemic disease. It is interesting to note that in localized disease sialic acid values stay within normal limits. 
Interestingly, considering the null expression of NeuGc in human somatic cells, the expression of NeuGc-GM3 in some human tumors was undoubtedly found. Yin et al. reported notable results supporting the idea that tumor hypoxia could be one of the factors responsible for the presence of the non-human sialic acids, such as NeuGc, in human tumors.

In this study sialic acid value remains constant throughout the duration of remission of the disease or disease-free interval (40). Thus, sialic acid cannot be used as a marker for early detection of disease, namely the localized disease. Increased levels have always coincided with disease progression and distant metastasis. In the case of the 2 patients the sialic acid began to increase before the time of imagistic diagnosis of distant metastases. This suggests that it could be an early marker of distant metastasis, indicating systemic disease.

A lot of studies revealed the possibility that sialylation/desialylation of some relevant molecules, such as tyrosinase itself and melanosomal sialoglycoconjugates, participates in the regulation of expression of melanogenic functions. It may also be possible that the differing extents of cell surface sialylation work as a signal for cell differentiation: cell surface sialic acid expression has been shown to undergo changes during normal melanocyte differentiation (46). It is likely that further studies focused on sialoglycoconjugates will help elucidate yet unidentified molecules that are involved in melanocytic cell differentiation.

Since NeuGc-GM3 is a postulated tumor antigen in human cancers development of NeuGcpositive murine tumor cells, it allows the possibility to evaluate cancer vaccines in animal models.

\section{Conclusions}

B16 melanoma cells are highly metastatic and form colonies of tumor nodules in the lung.

In the present study sialic acid level was drastically increased in the control meta- static tumor-bearing animals when compared to normal animals. Higher levels of cell surface sialic acid have been previously shown to correlate with the metastatic potential of tumor cells.

Determination of total serum sialic acid would be more useful for diagnosis of advanced melanoma stage and prognosis rather than for early detection and screening.

The sialic acid could be a marker of the metastatic disease, even before imagistic evidence of distant metastases.

The sialic acid assay is more reliable, less expensive, requires less technical sophistication, does not use radioactive reagents, and would lend it to automations.

The clinical significance of sialic acid measurement needs to be evaluated in a variety of human malignancies.

\section{References}

1. Hayat MJ, Howlader N, Reichman ME, Edwards BK. Cancer statistics, trends, and multiple primary cancer analyses from the Surveillance, Epidemiology, and End Results (SEER) Program. Oncologist. 2007 Jan;12(1):20-37.

2. DeVita V, Lawrence T, Rosenberg S. Principles \& Practice of oncology, 9th edition. 2011;119:1660-76.

3. Ross MI, Stern SJ. Mucosal Melanomas. St. Louis Quality Medical Publishing Inc. 1998;3:195-208.

4. Chang P, Knapper WH. Metastatic Melanoma of Unknown Primary. Cancer. 2006;49(6):1106-11.

5. Murali R, Shaw HM, Lai K, et al. Prognostic Factors in Cutaneous Desmoplastic Melanoma: A Study of 252 Patients. Cancer. 2010;116(17):4130.

6. Schrohl AS, Anderson MH, Sweep F, Schmitt M, Harbeck N, Foekens J, et al. Tumor Markers: From Laboratory to Clinical Utility. Mol Cell Proteomics. 2003 Jun;2:378-87.

7. Wu JT. Diagnosis and Management of Cancer Using Serological Tumor Markers. Henry's Clinical Diagnosis and Management by Laboratory Methods. 2007; 21: 4752.

8. Gershou YL, Stanley H, Jules H, John MJ. ASCO 2006 Update of Recomandations for the Use of Tumor Markers in Colon Cancer. Jurnal of Clinical Oncology. 2006 Jun;6:23-26.

9. McShane LM, Altman DG, Sauerbrei W, Taube SE, Gion M, Clark GM. Reporting Recommendations for Tumor Marker Prognostic Studies. Journal of Clinical Oncology. 2005;23(36): 9067-72.

10. Clinical Practice Guidelines for the Use of Tumor 
Markers in Breast and Colorectal Cancer. Adopted on May 17, 1996, by the American Society of Clinical Oncology. Journal of Clinical Oncology. 1996;14:2843-77. 11. International Germ Cell Consensus Classification: A Prognostic Factor-based Staging System for Metastatic Germ Cell Cancers. International Germ Cell Cancer Collaborative Group. Journal of Clinical Oncology. 1997;15:594-603.

12. Eriksson B, Oberg K, Stridsberg M. Tumor Markers in Neuroendocrine Tumors. Digestion International Journal of Gastroenterology. 2000;62:33-38.

13. Sturgeon C. Practice Guidelines for Tumor Marker Use in Clinic. Clin Chem. 2002;48:1151-59.

14. Locker GY, Hamilton S, Harris J. ASCO 2006 Update of Recommendations for the Use of Tumor Markers in Gastrointestinal Cancer. Journal of Clinical Oncology. 2006;24:5313-27.

15. National Comprehensive Cancer Network Clinical Practice Guidelines in Oncology. Non-Small Cell Lung Cancer. V.3.2011. Accessed at www.ncen.org on March 14, 2011.

16. Gajeroski TF, Grimm EA, Nickoloff BJ. New Potential Therapeutic Targets in Melanoma. ASCO Annual Meeting. 2008;123-125.

17. Narayanan S. Sialic Acid as a Tumor Marker. Ann Clin Lab Sci. 1994 Jul-Aug;24(4):376-84.

18. Dube HD, Bertozzi RC. Glycans in Cancer and Inflamation -potential for therapeutics and diagnostics. Nature Reviews Drug Discovery. 2005 June;4:477-448.

19. Feijoo C, Paez de la Cadena M, Rodriguez-Berrocal FJ, Martinez-Zorzano VS. Sialic Acid Levels in Serum and Tissue from Colorectal Cancer Patients. Cancer Lett. 1997;112:155-160.

20. Redondo-Garcia P, Nakamura CV, Souza W, Morgado-Diaz JA. Differential Expression of Sialic Acid and $\mathrm{N}$-acetyl-galactosamine Residues on the Cell Surface of Intestinal Epithelial Cells According to Normal or Metastatic Potential. J Histochem Cytochem. 2004 May;52:629-40.

21. Holzmann B, Brocker E, Lehmann MJ, Ruiter DJ, Sorg C, Riethmuller G. Tumor Progression in Human Malignant Melanoma: Five Stages Defined by Their Antigenic Phenotypes. International Journal of Cancer. 1987 April;39:466-71.

22. Silver HK, Rangel DM, Morton DL. Serum Sialic Acid Elevations in Malignant Melanoma Patients. Cancer. 1978;41(4):1497-99.

23. Taylor G. Sialidases: Structures, Biological Significance and Therapeutic Potential. Curr Opin Struct Biol. 1996;6:830-37.

24. Watkins E, Anderson I, Nebril LR, Waters IF, Connery CK. Neuraminidase-mediated Augmentation of in Vitro Immune Response of Patients with Solid Tumors. Int. J. Cancer. 2007;14:799-805.

25. Ros-Bullon MR, Sanchez-Pedreno P, Martinez-Liarte JH. Serum Sialic Acid in Malignant Melanoma Pa- tients: an ROC Curve Analysis. Anticancer Res. 1999 JulAug;19(4C):3619-22.

26. Miyata M, Kambe M, Tajima O, Moriya S, Kondo $\mathrm{Y}$, Narimatsu $\mathrm{H}$, et al. Membrane sialidase NEU3 is Highly Expressed in Human Melanoma Cells Promoting Cell Growth with Minimal Changes in the Composition of Gangliosides. Cancer Science. 2011 Dec;102:2139-49.

27. Miyagi T, Wada T, Yamaguchi K. Roles of Plasma Membrane-associated Sialidase NEU3 in Human Cancers. Biochim Biophys Acta. 2008;(7):532-78.

28. Suzuki Y, Ito T, Suzuki T. Sialic Acid Species as a Determinant of the Host Range of Influenza A Viruses. J Virol. 2000;74:11825-831.

29. Lehmann F, Tiralongo E, Tiralongo J. Sialic Acid Specific Lectins: Occurrence, Specificity and Function. Cell Mol Life Sci. 2006;63:1331-54.

30. Katterman R, Kriege R. Chem. Biochem. 1981;19(1):31-4.

31. Kinoshita Y, Sato S, Takeuchi T. Cellular Sialic Acid Level and Phenotypic Expression in B16 Melanoma Cells: Comparison of Spontaneous Variations and Bromodeoxyuridine-and Theophylline-Induced Changes. Cell Structure and Function. 1989;14:35-43.

32. Korangath Preethi C, Kodappully Siveen S, Kuttan R, Kuttan G. Inhibition of Metastasis of B16-F10 Melanoma Cells in C57BL/6 Mice by an Extract of Calendula Officinalis L Flowers. Asian Pacific Journal of Cancer Prevention. 2010;11:1773-79.

33. Schauer R. Sialic Acids as Regulators of Molecular and Cellular Interactions. Curr Opin Struct Biol. 2009;19:507-514.

34. Lloyd KO, Furukawa K. Biosynthesis and Functions of Gangliosides: Recent Advances. Glycoconj J. 1998;15:627-36.

35. Wada T, Hata K, Yamaguchi K. A Crucial Role of Plasma Membrane-associated Sialidase in the Survival of Human Cancer Cells. Oncogene. 2007;26:2483-90.

36. Monti E, Bassi MT, Papini N. Identification and Expression of NEU 3, a Novel Human Sialidase- associated to the plasma membrane. Biochem J. 2000;349:343-51.

37. Kannagi R. Carbohydrate Antigen Sialyl Lewis Pathophysiological Significance and Induction Mechanism in Cancer Progression. Chang Gung Med J. 2007;30:189209.

38. Patra SK. Dissecting lipid raft facilitated cell signaling pathways in cancer. Biochim. Biophys. Acta. 2008 Apr;1785(2):182-206.

39. Schauer R. Achievements and Challenges of Sialic Acid Research. Glycoconj J. 2000;17:485-99.

40. Bardor M, Nguyen DH, Diaz S, Varki A. Mechanism of Uptake and Incorporation of the non-human Sialic Acid $\mathrm{N}$-glycolylneuraminic acid into human cells. J Biol Chem. 2005;280:4228-37.

41. Hedlund $\mathrm{M}$, Tangvoranuntakul $\mathrm{P}$, Takematsu $\mathrm{H}$, Long JM, Housley GD, Kozutsumi Y, et al. N-glycolylneuraminic Acid Deficiency in Mice: Implications for hu- 
man biology and evolution. Moll Cell Biol. 2007;27:434046.

42. Varki A. Glycan-based Interactions Involoving Vertebrate Sialic Acid Recognizing Proteins. Nature. 2007; 446:1023-9.

43. Gabri R, Otero L, Gomez D, Alonso D. Exogenous Incorporation of Neugc-rich Mucin Augments n-glycolyl Sialic Acid Content and Promotes Malignant Phenotype in Mouse Tumor Cell Lines. Journal of Experimental and Clinical Cancer Research. 2009;28:146-158.
44. Ohyama C. Glycosylation in Bladder Cancer. Int. J. Clin. Oncol. 2008;13:308-13.

45. Yin J, Hashimoto A, Izawa M, Miyazaki K, Chen GY, Tkematsu H, et al. Hipoxic Cultures Induces Expression of Sialin, a Sialic Acid Transporter and Cancer Associated gangliosides containing non-human sialic acid on Human Cancer Cells. Cancer Res. 2006;66:2937-45.

46. Engers R, Gabbert HE. Mechanism of Tumor Metastasis: Cell Biological Aspects and Clinical Implications. J. Cancer Res Clin Oncol. 2000;126:682-92. 